\title{
SHORT-COMMUNICATION
}

\section{Investigating the influence of social dominance on survival during a pukeko cull}

\author{
Jing Sheng Hing ${ }^{1 \dagger}$, Meghan R. Healey ${ }^{1 \dagger}$, Cody J. Dey ${ }^{1,2}$ and James S. Quinn ${ }^{1 *}$ \\ ${ }^{1}$ Department of Biology, McMaster University, Life Sciences Building, 1280 Main Street West, Hamilton, Ontario, \\ L8S 4K1, Canada \\ ${ }^{2}$ Present address: Great Lakes Institute for Environmental Research, University of Windsor, Windsor, Ontario, Canada \\ *Author for correspondence (Email: quinn@mcmaster.ca) \\ ${ }^{\dagger}$ Authors have contributed equally to the manuscript
}

Published online: 19 September 2016

\begin{abstract}
Lethal control of wildlife is commonly used by conservation practitioners for population control. In some areas of New Zealand, changes in land-use and management have led to large increases in pukeko (Porphyrio melanotus melanotus) range and numbers. This native rail is sometimes considered a pest species, as they are known to uproot vegetation including tree seedlings, grass and crops. Here, we provide the first data on mortality during a lethal control operation that aimed to reduce pukeko population size at Tawharanui Regional Park in the North Island of New Zealand. We combined mortality records with individual measurements and colour banding re-sighting data to determine whether sex or dominance influenced survival. We found that frontal shield size (a strong proxy for social dominance) did not significantly influence the probability of being culled. There was also no significant difference in the probability of being culled between sexes. Our study provides important insights into mortality in a native species during lethal control, which could influence population recovery and social dynamics.
\end{abstract}

Keywords: conservation; cull; dominance; lethal control; pukeko; wildlife management

\section{Introduction}

Lethal control of wildlife is commonly used by managers and conservation practitioners to achieve various objectives (Treves \& Naughton-Treves 2005; McManus et al. 2013). In some situations, lethal control can be an effective conservation tool by preventing the spread of disease, decreasing predation pressure on threatened species, and/or minimising human-wildlife conflict (Treves \& Naughton-Treves 2005). Additionally, lethal control methods are often lower-cost and less labour intensive than alternative non-lethal techniques such as animal translocation (Linnell et al. 1997; McManus et al. 2013) or administering contraceptives (Massei \& Miller 2013; Raiho et al. 2015). Lethal control methods have sometimes been highly controversial, in part because of ethical issues associated with killing wildlife and partly because of the mixed outcomes of some projects (Treves \& Naughton-Treves 2005). For example, European badgers (Meles meles) have been culled in the United Kingdom for over three decades to prevent the transmission of bovine tuberculosis (TB) to cattle. However, one analysis comparing areas in which badgers were culled with areas that were not culled showed that the incidence of TB increased in cattle in areas where badgers were culled, bringing into question culling efforts and policies (Donnelly et al. 2003). Similarly, in a recent pūkeko (Porphyrio melanotus melanotus) cull, four Takahē (P. notornis hochstetteri), a critically endangered New Zealand endemic rail, were accidentally killed in the process, demonstrating that the practice of lethal control can have unforeseen ecological or conservation issues. With the increased awareness and support of animal rights and ethics, the tolerance for lethal control has generally decreased
(Hadidian et al. 2002; Kirkpatrick \& Frank 2005; Jackman \& Rutberg 2015). As a result, there is now a need to justify the use of these methods with robust scientific evidence on their effectiveness and the consequences for managed populations (Warburton \& Norton 2009).

Exotic terrestrial mammalian predators have had a significant impact on New Zealand's biodiversity, especially on native avian species (Innes et al. 2010). To help conserve native fauna, many areas of New Zealand are subject to predatorcontrol programs. The pūkeko is a native New Zealand rail that has proliferated due to changes in land-use and in some places has become a pest (Dey \& Jamieson 2013). Their foraging habits can result in the uprooting of vegetation, including crops, tree seedlings and grass in livestock paddocks (Dey \& Jamieson 2013). Additionally, pūkeko may prey on the young of other bird species. As a consequence, pūkeko are sometimes culled under permit despite limited knowledge of this practice on pūkeko populations and the wider ecosystem.

Removing individuals from a population (e.g. through lethal or non-lethal control) can have a variety of impacts on population dynamics, including alterations to social networks and dominance hierarchies (Caughley et al. 1992; Shannon et al. 2013). This effect has been shown in experimental, theoretical and field studies where individuals are removed from their social groups (Monnin \& Peeters 1999; Barrett et al. 2012; Kubitza et al. 2015). Such potential impacts should be investigated given that dominance relationships influence reproductive success in a variety of species (Ellis 1995) and therefore are likely to influence population growth rates. Additionally, if the chance of removal is biased towards individuals with specific traits then lethal control could cause 
rapid evolutionary changes similar to those documented in populations subjected to hunting and fishing (Ginsberg \& Milner-Gulland 1994; Swenson et al. 1997; Milner et al. 2007; Biro \& Post 2008). Directed lethal and non-lethal control could take advantage of these relationships to reduce population growth and/or eliminate specific personality traits associated with problem individuals (Caughley et al. 1992; Julien 2007; McCarthy et al. 2013). However, achieving such management goals requires a strong understanding of patterns of mortality during lethal control programs, particularly if one category of individuals is more likely to be culled than others (Linnell et al. 1999; Treves \& Naughton-Treves 2005). Therefore, it is important to study potential biases that may exist in lethal control practices and how these may have legacy effects in populations and the wider ecosystem.

Here, we provide the first data on the influence of lethal control on pūkeko by investigating whether there is a sexbias among culled individuals and whether social dominance influences the probability of being culled. Since dominance relationships and social group structure influence reproductive success (Ellis 1995), understanding the influence of these variables on the probability of being culled will provide a valuable insight into population dynamics after a lethal control program. Abetter understanding of sex-and dominance-specific mortality would help determine optimal target reductions for lethal control and conservation goals. Pūkeko live in complex social groups (Dey \& Jamieson 2013) that are structured as dominance hierarchies (Dey \& Quinn 2014; Dey et al. 2014a). In this species, dominance interactions are known to differ between the sexes and are influenced by the size of the frontal shield ornament, which acts as a badge of status (Rowher 1975; Dey et al. 2014a). We hypothesised that dominant individuals would have greater exposure to the poisoned bread used to cull adults, since dominant individuals have been observed to have priority access to food (Dey \& Quinn 2014). As a result, we predicted that dominant individuals would be more likely to be killed than subordinates. We also hypothesised that males would have greater mortality than females because they tend to be the first ones to approach novel objects (C. Dey pers. obs.) and are typically dominant over females (Jamieson \& Craig 1987). Therefore, we predicted that male pūkeko would more likely be killed than female pūkeko. By conducting these analyses, we hoped to understand potential patterns of biased mortality that may arise as a result of pūkeko culls and their potential consequences for population dynamics.

\section{Materials and methods}

\section{Field methods}

The study was conducted at Tawharanui Regional Park, located in the North Island of New Zealand $\left(36.3700^{\circ} \mathrm{S}, 174.8000^{\circ}\right.$ E). At this location pūkeko live in cooperative breeding groups that typically contain multiple breeding males and one to three breeding females that lay eggs in a shared nest. Groups may also include nonbreeding helpers of both sexes (sex ratio of study population pre-cull: $n=149$ females, $n=107$ males) that aid in raising the chicks. Pūkeko at this site have been studied since 2008 (Dey et al. 2014a), which has resulted in captures of a large number of individually colour-banded birds. Shield width, bill depth, shield-to-tip, nares-to-tip, tarsus length, wing chord and mass measurements were recorded at each capture event. Additionally, approximately $200 \mu \mathrm{L}$ of blood was sampled from the brachial vein using a $1 \mathrm{ml}$ syringe at each capture event. Group membership of banded adults was determined from detailed behavioural observations of territorial and non-territorial interactions (physical aggression as well as dominant and submissive postures; Craig 1977; Dey et al. 2014a) from a camouflaged hide. Information on trapping and banding methods can be found elsewhere (Dey \& Quinn 2014; Dey et al. 2014a, b). Animal trapping and handling protocols were approved through permits from the McMaster University Animal Research Ethics Board (\#13-10-37), the New Zealand Department of Conservation (DOC) Wildlife Authority (39641-FAU) and the DOC High Impact Research and Collection Permit (35048-FAU).

\section{Lethal control methods}

Between May and August 2014, 600 pūkeko were culled from Tawharanui as a means of population control under permit 38671-FAU from DOC. Contractors for Auckland Council undertook the cull. Of the 600 birds that were killed, 108 were banded from previous studies. Our sample includes culled individuals that were banded $(n=93)$, as well as banded members from their social groups that survived the cull (observed pre- and post-cull; $n=83$ ). Culled birds that did not have pre-cull shield measurements $(n=17)$ were excluded from this analysis.

The cull was undertaken to reduce a rapidly increasing pūkeko population (72\% increase from 2010 to 2013; C. Dey unpubl. data). Auckland Council wished to determine if a drop in their numbers would improve the success of re-vegetation attempts and breeding of other native fauna at the park. Pūkeko are known for pulling up freshly planted vegetation and have been observed to depredate pāteke (Anas chlorotis) and paradise shelduck (Tadorna variegate) ducklings (M. Maitland, Senior Ranger - Open Sanctuaries, Auckland Council, pers. comm.).

Tawharanui includes a number of paddocks used for raising cattle and sheep. Targeted paddocks $(n=9)$ were surveyed for groups of pūkeko and a coloured stake was placed at each location where adult pūkeko had been spotted congregating. Pre-feeding with 12 small pieces of buttered bread at each stake was carried out for five days prior to the poisoning and the baits were monitored to confirm that pükeko, and not other species, were taking the bread. After pre-feeding, the same number of poison baits (bread laced with alpha-chloralose) were placed at the stakes. Since alpha-chloralose acts as a narcotic, individuals were collected after consumption of poisoned bait and euthanized by cerebral percussion (i.e. a blow to the head). As a result, the direct cause of death for some birds was not the poison per se. Park personnel closely monitored activity at the baited stakes, therefore we are confident that few to no individuals that fed on the bait survived the poisoning. A post-mortem examination was completed by two researchers from Massey University. Shield and bill morphometrics were measured using calipers $( \pm 0.1 \mathrm{~mm})$ and sex was determined by inspection of the gonads.

\section{Molecular sexing}

Molecular sexing was conducted to: (1) evaluate the accuracy of a novel technique to molecularly sex pūkeko by assessing the frequency with which molecular sexing (i.e. gel image scoring) correctly sexed culled birds (i.e. those whose true sex was known from gonadal examinations); and (2) determine the sex of birds that survived the cull. 
Most of the birds in our study were molecularly sexed $(n=$ 161 molecularly sexed) with the exception of 15 individuals for which we did not have blood samples. These birds were sexed using discriminant function analyses using measurements of nares to tip, bill depth, shield width and head length (culmen length + shield length) (Craig et al. 1980). Discriminant function based sex determination has been used to sex pūkeko (Craig et al. 1980; Dey \& Quinn 2014) and is 89\% accurate based on our sample of culled birds (JS Hing unpubl. data). Briefly, DNA was extracted via phenol-chloroform protocols and the DNA stock solution was diluted tenfold in Tris-EDTA (TE) buffer prior to Polymerase Chain Reaction (PCR). We then targeted the Nipped-B homolog (NIPBL) gene (Suh et al. 2011) following PCR conditions outlined in Griffiths et al. (2002). PCR products were then separated by electrophoresis for 90 minutes at $117 \mathrm{~V} \mathrm{~cm}^{-1}$ in a $2 \%$ agarose gel stained with $7 \mu$ L Redsafe.

\section{Statistical analysis}

All analyses were conducted in $\mathrm{R}$ version 3.1.2 ( $\mathrm{R}$ Core Team 2015), using the lme4 (Bates et al. 2014) package. We used a generalized linear mixed model (GLMM) with a binomial error to evaluate the effect of frontal shield size and sex on survival. Male pūkeko are generally larger than females (Jamieson \& Craig 1987; Dey et al. 2014a); however, shield size does not significantly differ between the sexes after controlling for sex differences in body size (Dey et al. 2014a). Morphometric measurements for shield size from the most recent capture that preceded the cull (mean $=823.53$ days, $\mathrm{SD}=37.18$ ) were used for this analysis. For individuals that were culled (and therefore available for measurement), pre-cull measurements of shield size were significantly predictive of morphometry at the time of the cull (shield size: $n=93, R^{2}=0.26, P<0.001$ ). Both descriptive and experimental evidence suggests that shield size is a signal of dominance in pūkeko (Craig 1977; Dey \& Quinn 2014; Dey et al. 2014a). The response variable was survival, coded as a binary variable ( $1=$ survived, $n=83$ : males $=49$, females $=34 ; 0=$ did not survive, $n=93:$ males $=49$, females $=44$ ). Paddock ID was included as a random intercept in this model to account for statistical non-independence of birds that were subject to similar lethal control effort. Since the number of individuals that survived or were culled was $<5$ for some paddocks, we fitted models with the Laplace approximation, as recommended by Bolker et al. (2008). We checked the assumptions of the model by looking at residuals versus fitted, quantile-quantile and scale location plots. We also looked at the ratio of residual deviance to residual degrees of freedom to check for over dispersion.

\section{Results}

Sex assignment by inspection of the gonads and molecular sexing matched for 90 out of $91(98.9 \%)$ of the culled birds for which we had blood samples. The one mismatch was sexed as male by gonadal inspection but was confirmed as female multiple times when molecularly sexed.

Shield size did not significantly affect the probability of survival (estimate $=0.021,95 \% \mathrm{CI}=-0.068,0.11, \mathrm{Z}_{1}=$ $0.46, P=0.64$, see Figure 1 ). There was also no significant difference in the probability of survival between males and females (estimate [males] $=-0.22,95 \% \mathrm{CI}=-0.93,0.50, \mathrm{Z}_{1}$ $=-0.59, P=0.55)$.

\section{Discussion}

The costs and benefits of culling programs related to their desired outcomes for biodiversity protection are rarely investigated (Treves \& Naughton-Treves 2005; but see Magella \& Brousseau 2001; Donnelly et al. 2003). Culling undoubtedly has the potential to influence population demographics and

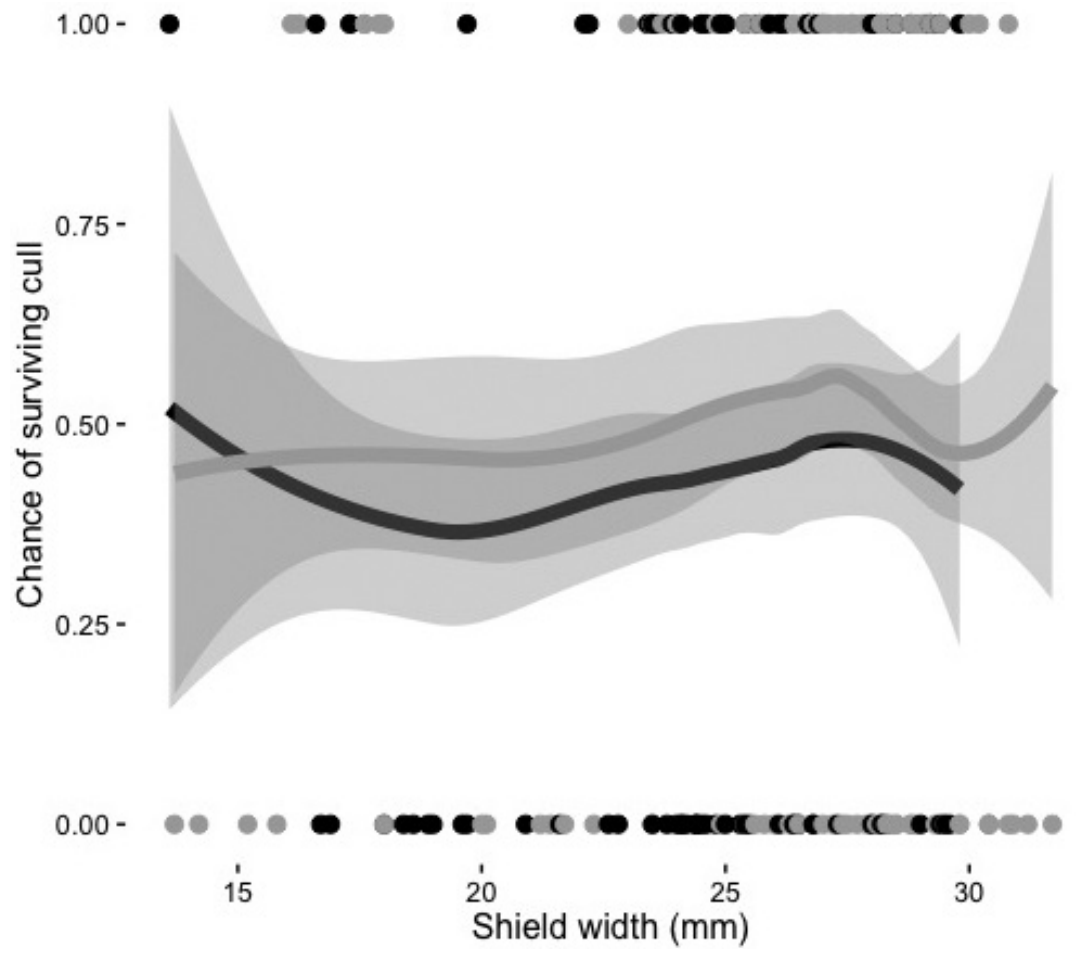

Figure 1. The relationship between shield width (a proxy for dominance) and survival of male and female pükeko ( $n$ $=176$ individuals pooled across nine paddocks). See methods for details of statistical analysis. Figure constructed using ggplot 2 (Wickham 2015). 
dynamics. We predicted that individuals with high dominance rank would suffer higher mortality rates during a cull of pūkeko. Contrary to what we predicted, dominant individuals were not less likely to survive. Increased mortality among dominant individuals was anticipated as they typically control access to food and were expected to monopolize access to poisoned bait. Since each piece of poisoned bread requires some handling time prior to consumption (M. Maitland pers. comm.), dominant individuals may have displaced subordinate individuals from the poisoned bait for prolonged periods of time. However, even if dominant individuals do displace subordinate individuals from feeding, subordinates may have been able to feed prior to the dominant individual's arrival or once the poison bait started to exert its effect on dominant birds, increasing their probability of being culled. This may explain the lack of an effect of dominance on the probability of being culled.

Additionally, our results suggest that there was no significant difference in the probability of survival between the sexes. Previous research has shown that culls targeted towards a specific sex can yield different responses in population dynamics (Mysterud et al. 2002; Gaillard et al. 2003; Gordon et al. 2004) and are likely to depress population growth, particularly when post-cull sex ratios are extremely asymmetrical (Gordon et al. 2004). Since sex-biased survival can influence population growth (Mysterud et al. 2002; Gaillard et al. 2003), its potential consequences should be considered prior to culling operations. However, to our knowledge, no prior study has examined patterns of mortality during pūkeko culls. Since we did not observe a sex-bias in mortality during the cull, we predict that post-cull population growth will be rapid. Large-scale culls of pūkeko have been conducted previously at Tawharanui (e.g. in 2008), suggesting that the current frequencies of culls should be evaluated alongside the costs and benefits of culls when maintaining pūkeko populations below the size that managers desire.

Given that lethal control of pūkeko is expected to continue and this study is the first to assess the consequences of pūkeko culls, we provide insight into the possible implications of lethal control on pūkeko. In social species, the removal of individuals can have a drastic influence on social dynamics and reproductive behaviour. For example, in many cooperative breeders, breeding by subordinate individuals is socially suppressed by dominant individuals (Poiani \& Fletcher 1994; Cant 2000; Schoech et al. 2004; Bell et al. 2014) and the selective removal of dominant individuals (i.e. through lethal control) may provide males and/or females of lower dominance rank and competitive ability with access to breeding opportunities. Following this cull, extremely large pūkeko clutches (total clutch size $=15$ or more eggs; compared with a typical average of five; Dey \& Jamieson 2013) were observed, which may have been due to disruption, in some social groups, of stable dominance hierarchies that typically dictate access to copulations and egg laying (Jamieson \& Craig 1987; Dey \& Quinn 2014).

Lethal control could also select for different personalities, which could influence the nature of social dynamics in surviving populations and future human-wildlife conflict. While we failed to observe a bias in mortality related to dominance rank, this does not exclude the possibility that bold individuals were the first to approach the poison bait and suffer higher mortality. Animal personalities have been described in many bird species and been shown to be heritable (Wilson et al. 1994; van Oers et al. 2003, 2004; Groothius \& Carere 2005). Since most lethal control programs predominantly eliminate bold individuals
(Linnell et al. 1999; Treves \& Naughton-Treves 2005), they could cause rapid population-level selection similar to that produced by hunting (Mysterud 2011). Future research that includes measurements of personality (e.g. across the shy-bold spectrum) in individual pükeko, the plasticity of personalities and possible correlates with other traits would be useful to understand potential selective influences of culls on pūkeko populations.

\section{Acknowledgements}

We would like to thank Ben Bolker, Jonathan Dushoff and Joshua Robertson for statistical advice. Matt Maitland provided cull records and allowed us to inspect the carcasses of culled birds. We would also like to thank Ngati Manuhiri (the manawhenua for the site) for granting us access to the bodies and supporting our use of the pūkeko for research purposes. Matt Maitland, George Perry, Margaret Stanley and two anonymous reviewers also provided helpful comments that improved the manuscript. We also thank the Tawharanui Open Sanctuary Society and the Tawharanui Regional Park staff. Finally, we thank Jessica Hiscox and James Dale(Massey University, Albany, Auckland, NZ) for collecting data on our culled birds.

\section{References}

Barrett L, Henzi SP, Lusseau D 2012. Taking sociality seriously: the structure of multi-dimensional social networks as a source of information for individuals. Philosophical Transactions of the Royal Society of London, Series B: Biological Sciences 367: 2108-2118.

Bates D, Maechler M, Bolker BM, Walker S 2014. lme4: linear mixed-effects models using Eigen and S4. Version 1.1.10. http://CRAN.R-project.org/package=1me4 (accessed 8 August 2015).

Bell MBV, Cant MA, Borgeaud C, Thavarajah N, Samson J, Clutton-Brock TH 2014. Suppressing subordinate reproduction provides benefits to dominants in cooperative societies of meerkats. Nature Communications 5: 4499.

Biro PA, Post JR 2008. Rapid deletion of genotypes with fast growth and bold personality traits from harvested fish populations. Proceedings of the National Academy of Sciences of the United States of America 105: 2919-2922.

Bolker BM, Brooks ME, Clark CJ, Geange SW, Poulsen JR, Stevens MHM, White JSS 2008. Generalized linear mixed models: a practical guide for ecology and evolution. Trends in Ecology and Evolution 24: 127-135.

Cant MA 2000. Social control of reproduction in banded mongooses. Animal Behaviour 59: 147-158.

Caughley G, Pech R, Grice D 1992. Effect of fertility control on a population's productivity. Wildlife Research 19: 623-637.

Craig JL 1977. The behaviour of the pūkeko Porphyrio porphyrio melanotus. New Zealand Journal of Zoology 4: 413-433.

Craig JL, McArdle BF, Whettin PD 1980. Sex determination of the pūkeko or swamphen. Notornis 27: 131-133.

Dey CJ, Jamieson IG 2013. Pūkeko. In: Miskelly CM ed. New Zealand birds online. www.nzbirdsonline.org.nz (accessed 8 June 2015). 
Dey CJ, Quinn JS 2014. Individual attributes and selforganizational processes affect dominance network structure in pūkeko. Behavioral Ecology 25: 1402-1408.

Dey CJ, Dale J, Quinn JS 2014a. Manipulating the appearance of a badge of status causes changes in true badge expression. Proceedings of the Royal Society of London, Series B: Biological Sciences 281: 20132680.

Dey CJ, O'Connor CM, Quinn JS 2014b. Hatching order affects offspring growth, survival and adult dominance in the joint-laying Pūkeko Porphyrio melanotus melanotus. Ibis 156: 658-667.

Donnelly CA, Woodroffe R, Cox DR, Bourne JF, Gettinby G, Le Fevre AM, McInerney JP, Morrison WI 2003. Impact of localized badger culling on tuberculosis incidence in British cattle. Nature 426: 834-837.

Ellis L 1995. Dominance and reproductive success among nonhuman animals: a cross-species comparison. Ethology and Sociobiology 16: 257-333.

Gaillard JM, Loison A, Toïgo C 2003. Variation in life history traits and realistic population models for wildlife management: the case of ungulates. In: Festa-Bianchet M, Apollonio M eds. Animal behaviour and wildlife conservation. Washington DC, Island Press. Pp. 115-132.

Ginsberg JR, Milner-Gulland EJ 1994. Sex-biased harvesting and population-dynamics in ungulates - implications for conservation and sustainable use. Conservation Biology 8: $157-166$.

Gordon IJ, Hester AJ, Festa-Bianchet M 2004. The management of wild large herbivores to meet economic, conservation and environmental objectives. Journal of Applied Ecology 41: 1021-1031.

Griffiths R, Double MC, Orr K, Dawson RJG 2002.ADNAtest to sex most birds. Molecular Ecology 7: 1071-1075.

Groothius TGG, Carere C 2005. Avian personalities: characterization and epigenesis. Neuroscience and Biobehavioral Reviews 29: 137-150.

Hadidian J, Simon LJ, Childs MR 2002. The 'nuisance' wildlife control industry: animal welfare concerns. Proceeding of the 20th Vertebrate Pest Conference. University of California, Davis, USA. Pp. 378-382.

Innes J, Kelly D, Overton JM, Gillies C 2010. Predation and other factors currently limiting New Zealand forest birds. New Zealand Journal of Ecology 34: 86-114.

Jackman JL, Rutberg AT 2015. Shifts in attitudes towards coyotes on the urbanized east coast: the Cape Cod experience, 2005-2012. Human Dimensions of Wildlife: An International Journal 20: 333-348.

Jamieson IG, Craig JL 1987. Dominance and mating in a communal polygynandrous bird: cooperation or indifference towards mating competitors? Ethology 75 : 317-327.

Julien TJ 2007. Controlling coyotes in an urban environment - effective evaluation of requests by the general public for control services. Proceedings of the 12th Wildlife Damage Management Conference, Corpus Christi, Texas, April 9-12 2007. Pp. 358-363.

Kirkpatrick JF, Frank KM 2005. Contraception in free-ranging wildlife. In: Asa CS, Porton IJ eds. Wildlife contraception issues, methods, and applications. Baltimore, John Hopkins University Press. Pp. 195-220.

Kubitza RJ, Suhonen J, Vuorisalo T 2015. Effects of experimental perturbation of group structure on hierarchy formation and behaviour in house sparrows. Ornis Fennica 92: 157-171.
Linnell JD, Aanes R, Swenson JE, Odden J, Smith ME 1997. Translocation of carnivores as a method for managing problem animals: a review. Biodiversity \& Conservation 6: $1245-1257$

Linnell JDC, Odden J, Smith ME, Aanes R, Swenson JE 1999. Large carnivores that kill livestock: do "problem individuals" really exist? Wildlife Society Bulletin 27: 698-705.

McCarthy RJ, Levine SH, Reed MJ 2013. Estimation of effectiveness of three methods of feral cat population control by use of a simulation model. Journal of the American Veterinary Medical Association 243: 502511.

McManus JS, Dickman AJ, Gaynor, Smuts BH, Macdonald DW 2013. Dead or alive? Comparing costs and benefits of lethal and non-lethal human-wildlife conflict mitigation on livestock farms. Oryx 49: 687-695.

Magella G, Brousseau P 2001. Does culling predatory gulls enhance the productivity of breeding common terns? Journal of Applied Ecology 38: 1-8.

Massei G, Miller LA 2013. Nonsurgical fertility control for managing free-roaming dog populations: a review of products and criteria for field applications. Theriogenology 80: 829-838.

Milner JM, Nilsen EB, Andreassen HP 2007. Demographic side effects of selective hunting in ungulates and carnivores. Conservation Biology 21: 36-47.

Monnin T, Peeters C 1999. Dominance hierarchy and reproductive conflicts among subordinates in a monogynous queenless ant. Behavioral Ecology 10: 323-332.

Mysterud A 2011. Selective harvesting of large mammals: how often does it result in directional selection? Journal of Applied Ecology 48: 827-834.

Mysterud A, Coulson T, Stenseth NC 2002. The role of males in the dynamics of ungulate populations. Journal of Animal Ecology 71: 907-915.

Poiani A, Fletcher T 1994. Plasama levels of androgens and gonadal development of breeders and helpers in the bell miner (Manorina melanophrys). Behavioral Ecology and Sociobiology 34: 31-41.

R Development Core Team 2015. R: a language and environment for statistical computing. $\mathrm{R}$ version 3.1.2. Vienna, Austria, R Foundation for Statistical Computing. www.R-project.org (accessed 8 August 2015).

Raiho AM, Hooten MB, Bates S, Hobbs NT 2015. Forecasting the effects of fertility control on overabundant ungulates: white-tailed deer in the national capital region. PLoS ONE 10: e0143122.

Rowher S 1975. The social significance of avian winter plumage variability. Evolution 29: 593-610.

Schoech SJ, Reynolds SJ, Boughton RK 2004. Endocrinology. In: Koenig WD, Dickinson JLeds. Ecology and evolution of cooperative breeding in birds. Cambridge, Cambridge University Press. Pp. 128-141.

Shannon G, Slotow R, Durant SM, Sayialel KN, Poole J, Moss C, McComb K 2013. Effects of social disruption in elephants persist decades after culling. Frontiers in Zoology 10: 62.

SuhA, Kriegs JO, Brosius J, Schmitz J 2011. Retroposon insertions and the chronology of avian sex chromosome evolution. Molecular Biology and Evolution 28: 2993-2997.

Swenson JE, Sandegren F, Söderberg A, Bjärvall A, Franzén R, Wabakken P 1997. Infanticide caused by hunting of 
male bears. Nature 386: 450-451.

Treves A, Naughton-Treves L 2005. Evaluating lethal control in the management of human-wildlife conflict. In: Woodroffe R, Thirgood S, Rabinowitz A eds. People and wildlife: conflict or coexistence? Cambridge, Cambridge University Press. Pp. 86-106.

van Oers K, Drent PJ, Goede PD, van Noordwijk AJ 2003. Realized heritability and repeatability of risk-taking behaviour in relation to avian personalities. Proceedings of the Royal Society of London, Series B: Biological Sciences 271: 65-73.

Editorial board member: Margaret Stanley

Received 5 September 2015; accepted 28 May 2016 van Oers K, de Jong G, Drent PJ, van Noordwijk AJ 2004. A genetic analysis of avian personality traits: correlated, response to artificial selection. Behavior Genetics 34: 611-619.

Warburton B, Norton BG 2009. Towards a knowledge-based ethic for lethal control of nuisance wildlife. Journal of Wildlife Management 73: 158-164.

Wickham H 2015. ggplot2: elegant graphics for data analysis. Version 1.0.1. https://CRAN.R-project.org/ package $=$ ggplot 2 (accessed 26 February 2016).

Wilson DS, Clark AB, Coleman K, Dearstyne T 1994. Shyness and boldness in humans and other animals. Trends in Ecology and Evolution 9: 442-446. 